\title{
Editor's Corner
}

Language Lab Bibliography: A new bibliography of the language laboratory covering the years 1950-1972 has been published. The author, Walter F. Davison, is the Language Lab Director at the University of Pittsburgh. The bibliography contains more than 700 references grouped in categories such as methodology, hardware, software, etc. The bibliography costs $\$ 3.75$ and may be obtained from:

Publications Section

University Center for International Studies

218 Oakland Avenue

University of Pittsburgh

Pittsburgh, $\mathrm{Pa} .15260$

Languages and Business: At least one American business firm has become interested in teaching their employees a foreign language. An article in Training describes the development of Spanish and French language programs for the employees of a major corporation. The courses use individual cassette recorders and programmed tapes and texts which are packaged in an attache case. (Language House Inc. produces these programs.) Audio-active-compare capability is built into the Craig cassette recorders which are used. Two one-hour sessions per week with the lab materials are supplemented by a onehour "live" lesson. Some of these live lessons are conducted by telephone when it is inconvenient or impossible for employees to attend at their scheduled time. The company feels that the overall results of the program have been successful.

New Directory for Spanish Teachers: Cruzada Spanish Publications has published a listing of Spanish materials available from various companies. The directory is available at a cost of $\$ 2.00$ from Cruzada Publications, P.O. Box 1269, Homestead, Florida 33030. (A review of this directory will be published in a forthcoming edition of the NALLD Journal.)

Language Lab Manufacturers: Many manufacturers have dropped out of the language lab business in the last two or three years. For the 


\section{Editor's Corner}

information of our readers, Mr. Thomas R. Goldsworthy has supplied us with this partial list of companies that are still active in this field:

Sony Corporation of America

Learning Systems Division

47-47 Van Dam Street

Long Island City, New York

(Tel. AC 212, 361-8600)

Rheem Califone Company

Language Laboratory Products

5922 Bowcroft Street

Los Angeles, California 90016

(Tel. AC 213, 870-9631)

Telex Communication Division

Educational Products

9600 Aldrich Avenue, South

Minneapolis, Minnesota 55420

(Tel. AC 612, 884-4051)

Scott Engineering Sciences

1400 S.W. 8th Street

Pompano Beach, Florida 33060

(Tel. AC 305, 946.4470)

General Electronic Laboratories (GEL)

1085 Commonwealth Avenue

Boston, Massachusetts 02215

(Tel. AC 617, 783-0460)

$\mathrm{P} / \mathrm{H}$ Electronics

117 E. Helena Street

Dayton, Ohio 45404

(Tel. AC 513, 461-5898)

3M Minicom Division

Wollensak Language Labs

3M Center

St. Paul, Minnesota 55101

Visual Educom, Inc.

4333 South Ohio Street

Michigan City, Indiana 46360

(Tel. AC 219, 879-8311)

Readers or company representatives wishing to supply additional addresses may send this information to the editor. 